\title{
Listeria monocytogenes encephalitis associated with corticosteroid therapy
}

\author{
M. L. JOHNSON AND E. W. COLLEY \\ From the Central Middlesex Hospital, London
}

SYNOPSIS A fatal case of Listeria monocytogenes septicaemia and encephalitis is described. The infection was associated with steroid therapy given for necrotizing cutaneous vasculitis. Agglutinating antibodies were not detectable in the patient's serum. Reasons for the failure of apparently appropriate antibiotic therapy are discussed.

The increasing number of reports of listeriosis in man in recent years probably reflects a greater awareness of the disease rather than any change in its incidence. It is well recognized that the infection is more common in infancy and old age, and may complicate malignancy (Louria, Hensle, Armstrong, Collins, Blevins, Krugman, and Buse, 1967; Simpson, Leddy, and Hare, 1967). Corticosteroids have been shown to increase the susceptibility of experimental animals (Nordland, 1960; Miller and Hedberg, 1965) and $L$. monocytogenes infection associated with steroid therapy in man carries an extremely poor prognosis (Gray and Killinger, 1966).

\section{CASE REPORT}

The patient was a 70-year-old housewife who, when first seen, had firm subcutaneous nodules up to $5 \mathrm{~cm}$ in diameter on the limbs and trunk. She had had a rash on the arms and legs for three years. Some of the nodules subsequently showed central softening, necrosis, and ulceration. The only other symptom was of recent weight loss.

She had had three miscarriages when in her thirties; there were no live births.

Clinical examination showed no abnormalities other than bony deformities of the legs due to old rickets and the skin lesions.

A skin biopsy showed severe vasculitis in the middle and deep dermis with necrosis of the dermal collagen and subcutaneous fat. There was atypical endothelial proliferation, and infiltration by polymorphs and eosinophils with abundant nuclear dust (leucocytoclasis).

LABORATORY INVESTIGATIONS Haemoglobin was $8.2 \mathrm{~g}$ / $100 \mathrm{ml}$; WBC were $5,000 / \mathrm{ccm}$, and the ESR was $30 \mathrm{~mm}$ in $1 \mathrm{hr}$ (Westergren). The blood film was characteristic

Received for publication 13 October 1968. of iron-deficiency anaemia. The sternal marrow showed proliferation of cells of the myeloid series and numerous megakaryocytes. Erythropoiesis appeared to be depressed. There was an increase in normal plasma cells.

Total serum proteins were $5.5 \mathrm{~g} / 100 \mathrm{ml}$ (albumin $1 \cdot 7$ $\mathrm{g} / 100 \mathrm{ml}$, globulin $3.8 \mathrm{~g} / 100 \mathrm{ml}$ ). An electrophoretic strip was normal. Immunoglobulins were: IgG $11.0 \mathrm{mg} / \mathrm{ml}$, IgA $2.72 \mathrm{mg} / \mathrm{ml}$, and IgM $0.44 \mathrm{mg} / \mathrm{ml}$.

The serum calcium level was $8.2 \mathrm{mg} / 100 \mathrm{ml}$; inorganic phosphate $4.3 \mathrm{mg} / 100 \mathrm{ml}$; alkaline phosphatase 29 KingArmstrong units; serum iron $20 \mu \mathrm{g} / 100 \mathrm{ml}$; serum vitamin $\mathbf{B}_{12} 168 \mu \mu \mathrm{g} / \mathrm{ml}$; serum folate $0.2 \mathrm{mg} / 100 \mathrm{ml}$; 24-hour urine calcium excretion was $17.7 \mathrm{mg}$ and faecal fat excretion $13.7 \mathrm{~g}$ in three days.

A barium meal and follow through was normal. Skeletal radiographs showed previous rickets of femora and tibiae, osteoarthritic changes in the knee joints and degenerative changes in the cervical and lumbar spine but no evidence of osteomalacia.

D-xylose absorption, after a $25 \mathrm{~g}$ dose, showed a serum level at one hr of $15 \mathrm{mg} / 100 \mathrm{ml}$, and vitamin A absorption at a fasting level of $109 \mathrm{IU} / 100 \mathrm{ml}$ rose to $116 \mathrm{IU} / 100 \mathrm{ml}$ after vitamin A $(0.5 \mathrm{mg} / \mathrm{kg})$.

A jejunal biopsy showed a mosaic and convoluted appearance macroscopically and microscopically severe partial villous atrophy with moderate inflammatory changes.

PROGRESS AND TREATMENT Following the diagnosis of vasculitis the patient was treated with prednisone, $20 \mathrm{mg}$ bd, and was given iron sorbitol citric acid complex, $2 \mathrm{ml}$ daily, for the anaemia. She improved steadily on this treatment. The subcutaneous nodules involuted, the erythema subsided, and the ulcerated lesions healed. The haemoglobin rose to $11.8 \mathrm{~g} / 100 \mathrm{ml}$.

Three weeks after starting steroids and when the prednisone had been reduced to $20 \mathrm{mg}$ daily she suddenly developed a fever of $102^{\circ} \mathrm{F}\left(38.9^{\circ} \mathrm{C}\right)$. The chest radiograph, sputum, and white blood count were all normal. A Proteus infection was found in the urine and this was treated with 465 
ampicillin, $250 \mathrm{mg}$ qds. A blood culture was taken at the onset of the fever and six days later Listeria monocytogenes was isolated from it. Ampicillin was therefore continued for a total of two weeks and was followed by a 10-day course of tetracycline, $250 \mathrm{mg}$ qds. On this regime her temperature became normal.

Four days after the tetracycline was stopped, the patient became semicomatose and at the same time gradually developed a left-sided hemiplegia and basal bronchopneumonia. There was no neck stiffness and the fever of $101^{\circ} \mathrm{F}\left(38.3^{\circ} \mathrm{C}\right)$ was thought to be due to the pneumonia. She was given ampicillin, $500 \mathrm{mg}$ six hourly, but deteriorated and died one week later.

\section{BACTERIOLOGY}

L. monocytogenes was isolated from a blood culture after six days' incubation at $37^{\circ} \mathrm{C}$. The organism was a small Gram-positive bacillus with many coccoid forms. Cultural appearances were typical, the colonies on horse-blood agar showing a narrow zone of haemolysis. In broth cultures incubated at room temperature characteristic tumbling motility was seen. Acid with gas was produced in peptone water containing $1 \%$ of glucose, glycerol, trehalose, dextrin, xylose, rhamnose, sorbitol, arabinose, laevulose, maltose, and salicin. There was no oxidation or fermentation in adonitol, inositol, saccharose, raffinose, inulin, or dulcitol after 48 hours' incubation at $37^{\circ} \mathrm{C}$. The organism was shown to be of type 4.

ANTIBIOTIC SENSITIVITY TESTS By means of Oxoid multidiscs the organism was found to be sensitive to benzylpenicillin ( 1.5 units), streptomycin $(10 \mu \mathrm{g})$, tetracycline $(10 \mu \mathrm{g})$, erythromycin $(10 \mu \mathrm{g})$, cloxacillin $(5 \mu \mathrm{g})$, novobiocin $(5 \mu \mathrm{g})$, chloramphenicol (10 $\mu \mathrm{g})$, and ampicillin $(25 \mu \mathrm{g})$. It was resistant to nitrofurantoin $(50 \mu \mathrm{g})$, nalidixic acid $(30 \mu \mathrm{g})$, polymyxin B (100 units), and sulphafurazole (100 $\mu \mathrm{g})$. Using mast sensitivity discs the organism was also found to be sensitive to cephaloridine $(5 \mu \mathrm{g})$, kanamycin $(30 \mu \mathrm{g})$, lincomycin $(2 \mu \mathrm{g})$, neomycin $(10 \mu \mathrm{g})$, and fusidic acid $(10 \mu \mathrm{g})$.

AGGLUTINATION TESTS ON PATIENT'S SERUM Two specimens of serum taken 10 days and 22 days respectively from the onset of fever were tested.

Using a formalinized suspension of the organism isolated from the patient, tests for $H$ agglutinins were negative. In tests for $\mathbf{O}$ agglutinins a satisfactory suspension of the organism could not be prepared owing to a marked tendency to spontaneous agglutination.

Using strains of L. monocytogenes of types 1, 2, 3, and 4 (National Collection of Type Cultures, Colindale), $\mathbf{O}$ and $\mathbf{H}$ agglutinins were not detected in either specimen of serum.
ANIMAL PATHOGENICITY Three days after instilling a drop of broth suspension of the organism into the eye of a guinea-pig, purulent conjunctivitis developed. $\overrightarrow{\vec{F}}$ In Gram-stained films of the exudate Gram-positivebacilli were seen within mononuclear cells.

A guinea-pig was also injected intramuscularly $\frac{}{\overline{0}}$ with a broth culture of the organism and killed after $\mathbb{\nabla}$ six days. Areas of focal necrosis were seen in the liver both macroscopically and microscopically. ${ }^{\text {s }}$ Microscopically Gram-positive bacilli were also seen $\vec{\circ}$ in the spleen.

At the time of isolation of Listeria from the blood cultures, swabs were taken from the posterior응 vaginal fornix and from an unhealed lesion of the leg. Swabs were cultured at $37^{\circ} \mathrm{C}$ immediately after ${ }^{N}$ being taken from the patient, and also after storage at $4^{\circ} \mathrm{C}$ for three days. L. monocytogenes was not ${ }^{\circ}$ isolated from any of these swabs but at that time theo patient had already been treated with ampicillin for six days.

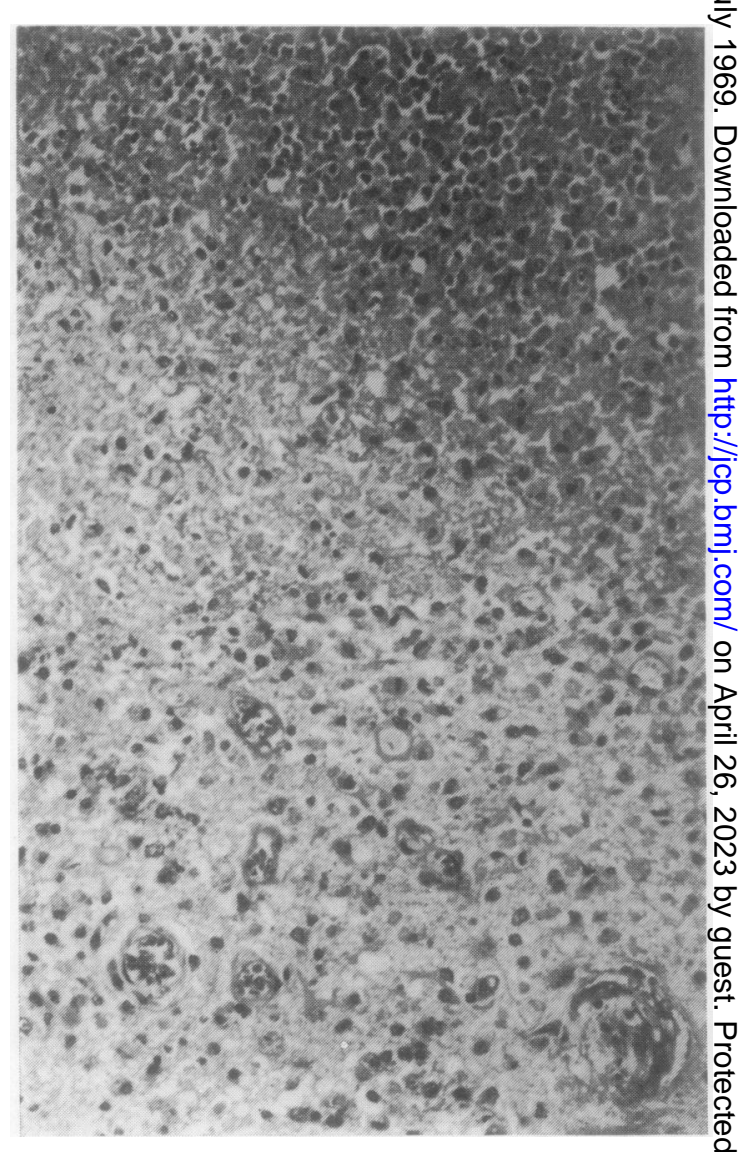

FIG. 1. Edge of microabscess showing increased vas cularity and fibrinoid necrosis in one vessel (haematoxyliñ and eosin $\times 100$ ). 


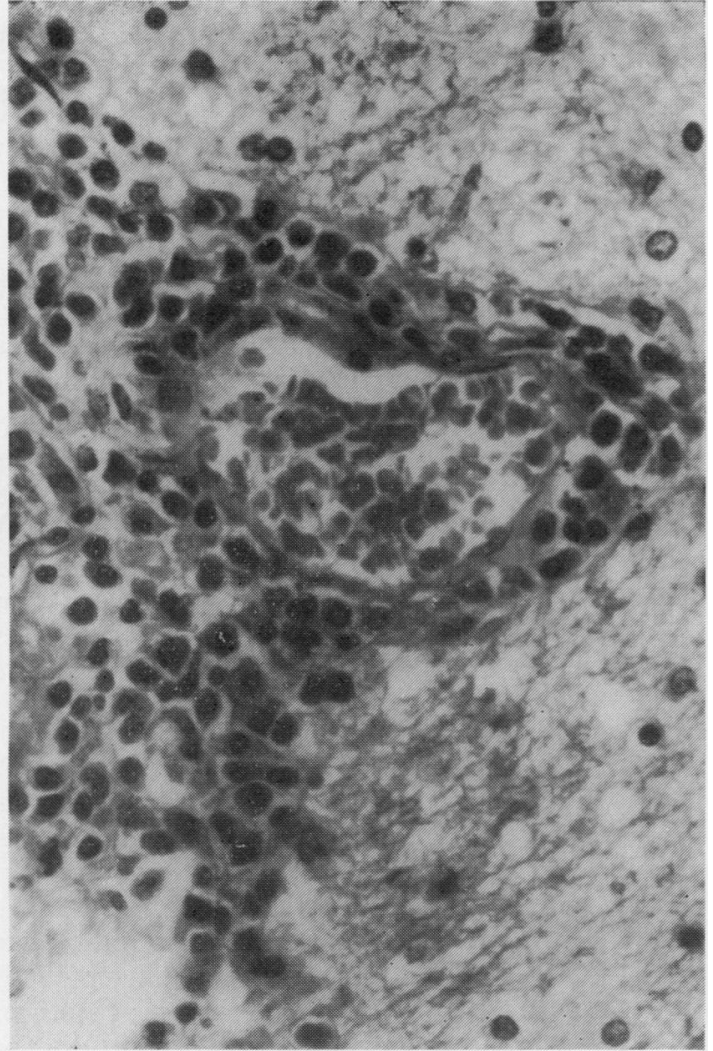

FIG. 2.

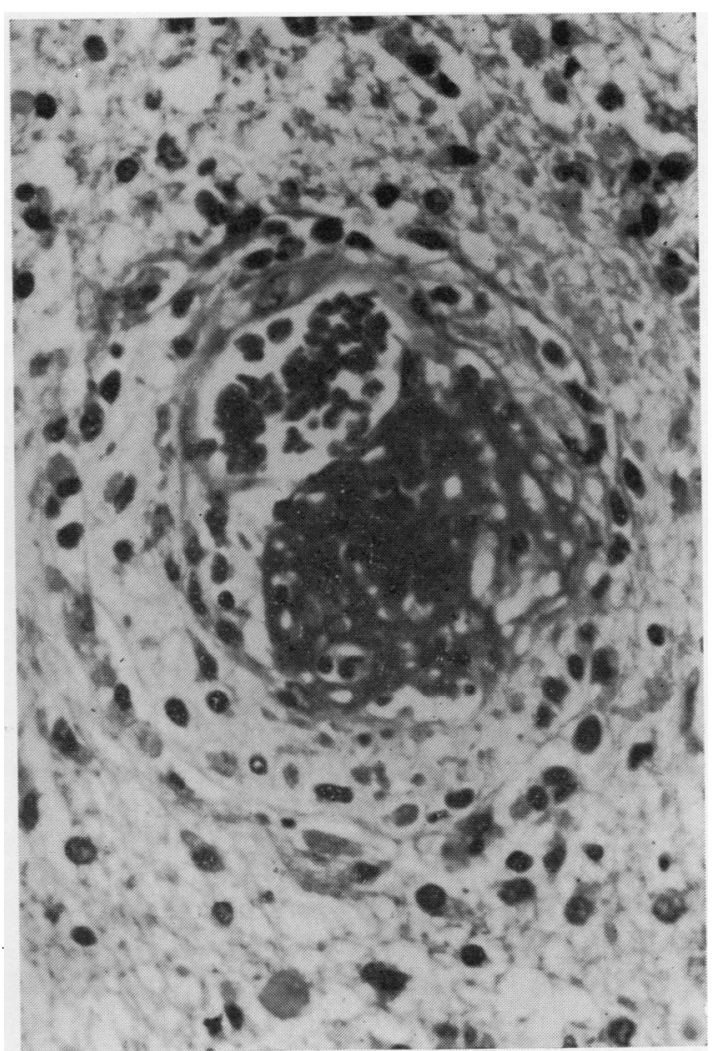

FIG. 3 .

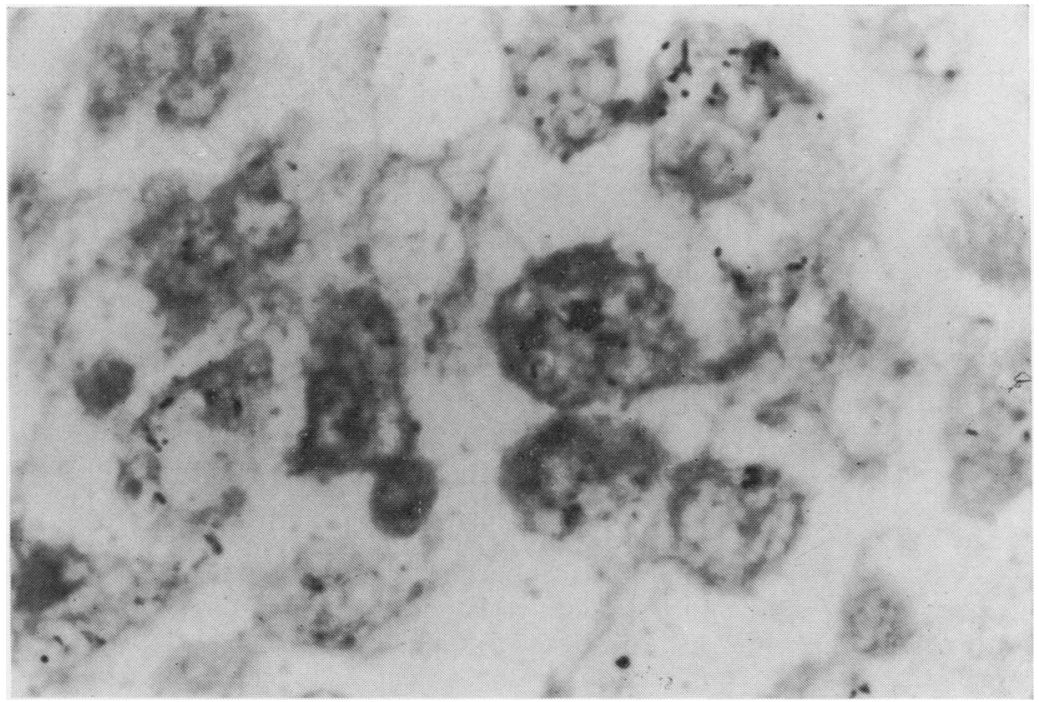

FIG. 2. Small vessel surrounded by lymphocytes, macrophages, and plasma cells $(H$ and $E \times 200)$

FIG. 3. Fibrinoid necrosis of vessel wall $(H$ and $E \times 300)$.

FIG. 4. Gram-positive coccobacilli in macrophage in the centre of a microabscess $($ Gram $\times 1,000)$.

FIG. 4. 


\section{NECROPSY FINDINGS}

BRAIN There was swelling of the right cerebral hemisphere caused by multiple small pale yellow abscesses up to $3 \mathrm{~mm}$ in diameter in the white matter of the right posterior frontal and parietal lobes, associated with oedema and softening. Over both hemispheres there was marked senile leptomeningeal thickening, but no other abnormality was seen.

Histology of brain In the cortex and white matter there were small abscesses in which the centres were necrotic and contained large numbers of Grampositive coccobacilli (Fig. 4) and the peripheral parts were infiltrated by macrophages. The tissue surrounding these was rich in blood vessels which were increased in number both in the cortex and the white matter (Fig. 1). Small recent haemorrhages were present at the periphery of some of the microabscesses and some of the vessels in these areas showed fibrinoid necrosis (Fig. 3).

The leptomeninges were infiltrated by plasma cells, macrophages, lymphocytes, and very occasional polymorphs. Similar cells surrounded many of the capillaries in the cortex and to a more marked degree in the white matter (Fig. 2).

LUNGS Confluent bronchopneumonia of both lower lobes was seen.

SKIN There was patchy pigmentation and scarring, mainly of the legs.

GASTROINTESTINAL TRACT This was macroscopically normal. Three sections at different levels of the small intestine showed partial villous atrophy on histological examination.

SPLEEN The spleen was atrophic, weighing $25 \mathrm{~g}$. CERVIX UTERI There was a purulent cervicitis and vaginitis.

The heart, blood vessels, liver, kidneys, bladder, and lymph nodes were normal.

POSTMORTEM BACTERIOLOGY Specimens of the following were cultured for $L$. monocytogenes: lung, hilar lymph nodes, myocardium, heart blood, liver, spleen, kidneys, brain, and cervix uteri. The medium used for culture was tryptose broth (Difco) to which had been added $0.004 \%$ nalidixic acid. Material from each specimen was emulsified and cultured in broth both at $37^{\circ} \mathrm{C}$ and at $4^{\circ} \mathrm{C}$ according to the method of Gray, Stafseth, Thorp, Sholl, and Rile (1948). Subcultures were made on to $5 \%$ horse blood agar.

None of the specimens incubated at $37^{\circ} \mathrm{C}$ grew listeria after 10 weeks' incubation. Of the material kept at $4^{\circ} \mathrm{C}$ a growth of $L$. monocytogenes was obtained from the brain after seven weeks, following subculture onto blood agar and incubation at $37^{\circ} \mathrm{C}$. Listeria was not isolated from any of the other material cultured.
A heavy growth of Klebsiella was obtained from culture of the lung.

\section{DISCUSSION}

The present case is unusual in that multiple small abscesses were confined to one cerebral hemisphere. $\overrightarrow{\mathrm{\Phi}}$ Eck (1957) reported seven cases of suppurative listerial encephalitis in which the brains were studdedes with pinpoint foci of necrosis. However, in his cases $\overrightarrow{0}$ and in those of Benazet, Sohier, and Bonjean (1957) and of Duffy, Sassin, Summers, and Lourie (1964) the microabscesses were confined to the pons and medulla. These reports mention the presence of perivascular cuffing, suppurative encephalitis, mul- N tiple small haemorrhages, and the absence of $f_{-}$ evidence of meningitis. Duffy, however, was the first to report the presence of fibrinoid necrosis of vessel walls in the affected part of the brain and ${ }_{-}^{\supset}$ similar changes were seen in the present case (Fig. 3). $C$ All these cases were fatal but a patient reported by Ford, Herzberg, and Ford (1968) with a diagnosis of $\vec{c}$ probable rhombo-encephalitis survived after anti-g biotic therapy including chloramphenicol, sulpha-diazine, and ampicillin; their patient was also ono prednisone for rheumatoid arthritis.

L. monocytogenes is sensitive to most antibiotics in vitro. Seeliger (1961) and Gray and Killinger (1966)\% consider that tetracycline is the drug of choice. McNair, White, and Graham (1968) described the $\vec{F}$ use of ampicillin in two cases of listerial meningitis. 3 In our case in spite of the administration of tetracycline and ampicillin the patient died and $L . ?$ monocytogenes was cultured at necropsy. It is, therefore, possible that either the resistance of the patient or the effectiveness of the drug against the 3 . organism may have been influenced by the cortico- 8 steroid therapy or by the necrotizing vasculitis.

The malabsorption syndrome may have led to low 0 blood concentrations of the antibiotics. Although the jejunal biopsy appearance was of partial villouso atrophy the IgM level $(0.44 \mathrm{mg} / \mathrm{ml})$, which was below the normal range, suggests that the patient may have $N$ had idiopathic steatorrhoea (Hobbs and Hepner, N 1968) and the atrophy of the spleen also supports this diagnosis.

Louria et al (1967) showed that administration of tetracycline and penicillin to mice inhibited the growth of $L$. monocytogenes in tissue but did not $\stackrel{\Phi}{?}$ eradicate the infection. Listeria monocytogenes, like the tubercle bacillus, is a facultative intracellular parasite and resistance to it is probably due to the $\mathbb{D}$ increased capacity of the macrophages to ingest and $\frac{\mathcal{D}}{\mathbb{P}}$ inhibit the organism rather than to any increase in 2 circulating antibody (Armstrong and Sword, 1964).

It is known that cortisone greatly increases the 
susceptibility to listerial infection and may reactivate listeriosis in experimental animals (Nordland, 1960; Miller and Hedberg, 1965). Gray (personal communication to Delta and Pinkel, 1962) stated that 12 out of 13 patients who contracted listeriosis while on steroid therapy died, and other fatal cases of septicaemic listeriosis complicating steroid therapy have been reported by Sobrevilla, Tedeschi, Cronin, and Kantrowitz(1962) and Seeliger (1961). The reason for this effect of corticosteroids is not known but various possibilities have been reviewed by Simpson et al (1967). Corticosteroids increase the infectivity of Aspergillus flavus in mice, and Epstein, Verney, Miale, and Sidransky (1967) suggested that this was due to stabilization of lysosomal membranes within the macrophages by the steroids, preventing the release of catabolic enzymes and destruction of the fungus. A similar mechanism might account for the reduced resistance to listerial infection in animals and man on steroid therapy, and for the poor response to antibiotics and survival of living bacteria.

Another possibility is that steroids may suppress antibody formation, and it is of interest that our patient had no detectable agglutinating antibodies to listeria although the IgG and IgA were quantitatively normal and the IgM only slightly reduced. However, little correlation has been found between serum antibody titres and the presence, absence, or recovery from listerial infection (Seeliger, 1961; Armstrong and Sword, 1964).

In our patient the necrotizing vasculitis may have contributed to the susceptibility to listeriosis. The aetiology of the various syndromes of necrotizing or allergic cutaneous vasculitis is unknown but it is thought that there may be a disturbance of immune mechanisms in some cases associated with bacterial sensitization (Winkelmann and Ditto, 1964). Whether this disturbance affects the cellular resistance to L. monocytogenes is not known, but cases of systemic lupus erythematosus (another disease accompanied by altered immunity) developing fatal listerial meningitis are described by Schulze, Wahle, and White (1953) and by Rosengarten and Bourn (1959). The patient of Schulze et al was not treated with corticosteroids but the other was given ACTH and prednisone.

The source of listerial infection in man is uncertain. The disease is widespread in animals and birds but apart from direct infection in veterinarians (Owen, Meis, Jackson, and Stoenner, 1960) the spread from animals to man has not been established. In the present case it is possible that the listerial infection may have been longstanding. Rappaport, Rabinovitz, Toaff, and Krochik (1960) suggested that one of their patients who had listerial infection of the genital tract associated with repeated abortions had had the infection for 14 years. The patient reported above had had three abortions 30 or more years before her final illness. However, the length of this interval makes it unlikely that these were listerial in origin. A cervicitis was present at necropsy but L. monocytogenes was not isolated in cultures taken from the posterior fornix before and after death.

We would like to thank Dr Etain Cronin for permission to report this case, Dr P. P. Anthony for the report of the necropsy findings, and Miss A. J. Tannahill of the Standards Laboratory, Colindale, for typing the organism and investigating the antibody levels. We also thank Dr C. E. D. Taylor for help and useful criticism.

\section{REFERENCES}

Armstrong, A. S., and Sword, C. P. (1964). J. infect. Dis., 114, 258. Benazet, F., Sohier, R., and Bonjean, M. (1957). Presse méd., 65, 2168. Delta, B. G., and Pinkel, D. (1962). J. Pediatrics., 60, 191.

Duffy, P. E., Sassin, J. F., Summers, D. S., and Lourie, H. (1964). Neurology (Minneap.), 14, 1067.

Eck, H. (1957). Schweiz. med. Wschr., 87, 210.

Epstein, S. M., Verney, E., Miale, T. D., and Sidransky, H. (1967). Amer. J. Path., 51, 769.

Ford, P. M., Herzberg, L., and Ford, S. E. (1968). Quart. J. Med., 37, 2, 81.

Hobbs, J. R., and Hepner, G. W. (1968). Lancet, 1, 217.

Gray, M. L., Stafseth, H. J., Thorp, F., Jr, Sholl, L. B., and Rile, W. F., Jr (1948). J. Bact., 55, 471.

- , and Killinger, A. H. (1966). Bact. Rev., 30, 309.

Louria, D. B., Hensle, T., Armstrong, D., Collins, H. S., Blevins, A., Krugman, D., and Buse, M. (1967). Ann. Intern. Med., 67, 261.

McNair, D. R., White, J. E., and Graham, J. M. (1968). Lancet, 1, 16.

Miller, J. K., and Hedberg, M. (1965). Amer. J. clin. Path., 43, 248.

Nordland, O. S. (1960). Canad. J. comp. Med., $24,19$.

Owen, C. R., Meis, A., Jackson, J. W., and Stoenner, H. G. (1960). New Engl. J. Med., 262, 1026.

Rappaport, F., Rabinovitz, M., Toaff, R., and Krochik, N. (1960). Lancet, 1, 1273.

Rosengarten, R., and Bourn, J. M. (1959). Neurology (Minneap.), 9, 704.

Schulze, M. L., Wahle, G. H., Jr, and White, J. B. (1953). Amer. J. clin. Path., 23, 1028.

Seeliger, H. P. R. (1961). Listeriosis. Hafner, New York.

Simpson, J. F., Leddy, J. P., and Hare, J. D. (1967). Amer. J. Med., 43, 39.

Sobrevilla, L. A., Tedeschi, L. K., Cronin, J. F., and Kantrowitz, W. (1962). Boston med. $Q ., 13,62$.

Winkelmann, R. K., and Ditto, W. B. (1964). Medicine (Baltimore), 